\title{
Effect of starter cultures on various classes of fatty acids in Sudanese fermented camel milk (Camelus dromedarius) gariss
}

\author{
Adam Ismail Ahmed ${ }^{1 *}$, Babiker Elwasila Mohamed², Nuha Mohamed elkhatim Yousif ${ }^{2}$, Bernard Faye ${ }^{3}$, \\ Gerard - Loiseau ${ }^{3}$ \\ ${ }^{1}$ Department of Biochemistry \& Food Science, Faculty of Natural Resources \& Environmental Studies, University of Kordofan, Elobeid, Sudan, \\ ${ }^{2}$ Department of Food Science and Technology, Faculty of Agriculture, University of Khartoum, Shambat, Sudan, ${ }^{3}$ International Co-operation \\ Center in Agronomic Research for Development CIRAD, Montpellier, France.
}

\section{A B S T R A C T}

\begin{abstract}
The objective of the present research was to study the variation of fatty acids classes in gariss (Sudanese fermented camel milk) prepared under controlled conditions (starter cultures and time of fermentation). Inoculations of raw camel milk with selected LAB strains (E. duransRO3, E.faecium NWL and L. plantarum BJ6 and their combination as well as the control - fermentation without starter cultures) was performed at varying periods of time (zero, 3, 6, 9 and $12 \mathrm{~h}$ ) at ambient temperature, then the role of these conditions on fatty acids classes were studied. Camel milk fermented under starter-culture controlled conditions contained unsaturated fatty acids, including the essential fatty acids. Considerable amounts of $\omega_{3}$ and $\omega_{6}$ fatty acids and the absence or presence of low amounts of short chain fatty acids were found compared to cow milk.
\end{abstract}

Keywords: Starter; Enterococcus; Fatty acids; LAB strains

\section{INTRODUCTION}

There are various traditional fermented camel milk products that are produced by camel herders in different parts of the world (Yagil, 1982; Abdelgadir et al., 1998; Lore et al., 2005; Hassan et al., 2008; Abdel Rahman et al., 2009; Konuspayeva and Faye, 2011). Fermented milk products such as suusac and gariss are produced from camel milk in Kenya, Somalia and Sudan (Abdelgadir et al., 1998; Lore et al., 2005).

Camel's milk is produced in certain areas of Sudan, under nomadic conditions. The camel's milk being abundant in remote localities, the camel herders have to prepare gariss, a fermented product, on which they sustain living for several months as the sole source of various nutrients (Dirar, 1993; Abdelgadir et al, 1998). Gariss is a special kind of fermented milk, prepared solely from camel milk under more or less shaking. Besides its use as food, camel milk has been used in many regions as a cure for certain diseases (Dirar, 1993; Abdelgadir et al., 1998; Suleiman et al., 2007). In the Horn of Africa, $10 \%$ of produced milk is derived from camels (Faye and Konuspayeva, 2012). However, most camel milk is produced in traditional farming or pastoral systems by hand milking that cannot provide consistent quantity and quality of raw milk for urban markets (Abeiderrahmane, 2005). The camel dairy industry, including machine milking, processing, and distribution, has been established in the last decade but it is still in an early stage of development (Nagy et al., 2013). Seifu et al. (2012) isolated and characterized lactic acid bacteria from Ethiopian traditional fermented camel milk, and they concluded that the isolated lactic acid bacteria species could be considered as potential candidates for development of starter cultures that can be used for the production of fermented camel milk products under controlled condition. Enterococcus species are known by their production of enterocins which exert different specific inhibition activity against pathogenic bacteria (Sabia et al., 2002).

\footnotetext{
*Corresponding author:

Adam Ismail Ahmed, Department of Biochemistry \& Food Science, Faculty of Natural Resources \& Environmental Studies, University of Kordofan, Elobeid, Sudan, P.O. Box .160. Phone: +249122245279, Mobile: +2489 0122245279. E-mail: adamalgnana62@yahoo.com
} 
The study of microflora in traditional fermented dairy products as gariss and preparation of starters is of a good concern. To obtain the gariss with better quality and to produce this traditionally fermented product at the industrial level with high quality, control starter cultures must be used. For many authors, the presence of enterococci is evidence of possible fecal contamination and therefore a risk to consumers because although these strains are known for their low virulence, they pose serious health problems due to the emergence of many antibiotic-resistant strains (Akhmetsadykova et al., 2014). The objective of the present work was to know the changes in the fatty acids classes of gariss prepared under controlled conditions in order to assess the influence of the strains used.

\section{MATERIALS AND METHODS}

Fermented camel milk (gariss) was prepared under controlled conditions. Inoculations of camel milk was performed for varying periods of time (zero, $3 \mathrm{~h}, 6 \mathrm{~h}, 9 \mathrm{~h}$ and $12 \mathrm{~h}$ ) at ambient temperature with selected LAB strains (E. duransR03, E.faecium NWL and L. plantarum BJ6 and their combination as well as the control, fermentation without starter cultures). The preparation of the starter culture to be inoculated with the specific strain in nonsterilized camel milk prepared in last $24 \mathrm{~h}$ (with the three strains i.e. E. duransR03, E.faecium NWL and L. plantarum $B J 6$ and their combination). That means we used pure strain inoculated in camel milk (non sterilized one) left for $24 \mathrm{~h}$, then it used for gariss preparation. A 3\% starter culture was used to prepare gariss, and then the fermentation was carried out according to the traditional gariss preparation methods. Five gariss batches (Batch $\mathrm{A}=\mathrm{E}$. duransR03, Batch $\mathrm{B}=$ E. faecium $\mathrm{NW}$, Batch $\mathrm{C}=\mathrm{L}$. plantarum $\mathrm{BJ} 6, \mathrm{~B}$ atch $\mathrm{D}=$ the combination and Batch $\mathrm{F}=$ the control - fermentation without starter culture) were prepared, and for each $500 \mathrm{ml}$ of camel milk 3\% batch, 24 hours starter cultures were inoculated. Batch one was inoculated with strain Enterococcus duransR03, batch two with strain E. faecium NWL, batch three with Lactobacillus plantarum BJ6, batch four consisted of a mixture of the strains at equal proportions and batch five was a control batch which was left uninoculated. The preparation was left to ferment for 12 hours at ambient temperature. Samples were withdrawn in 0, 3, 6, 9 and 12 hours to perform the fatty acids classes of the produced gariss.

\section{Fatty acid analysis}

From the extracted lipids, stored at $4^{\circ} \mathrm{C}$, the method of Konuspayeva et al. (2008) was used to prepare and quantify fatty acid methyl esters which were taken for analysis by GC system (Massy, France) mass spectrometry. The fatty acids were identified by comparison of retention time with known standards and were expressed as percentage of total fatty acids, and then the fatty acids classes were calculated.

\section{Definition of the fatty acid classes}

The fatty acids (FA) were grouped into different classes according to their carbon chain length or their carbon saturation status:

Short chain fatty acids (SCFA): All FA with few Carbone atoms between $\mathrm{C} 4$ and $\mathrm{C} 8$.

Medium chain fatty acids (MCFA): All fatty acids with medium carbon atoms between $\mathrm{C} 10$ and $\mathrm{C} 15$

Long chain fatty acids (LCFA): All fatty acids with many carbon atoms between C16 and C22:6

Saturated fatty acids (USFA): All fatty acids with saturated carbon atoms.

Mono-unsaturated fatty-acids (MUSFA): All fatty acids with one unsaturated carbon atom.

Poly-unstaurated fatty acids (PUSFA): All fatty acids with more than two unsaturated carbon atoms.

\section{Statistical analysis}

Statistical Packages for Social Sciences (SPSS 16.00) was used to analyze data using ANOVA and Duncan Multiple Range Test (DMRT) for mean separation.

\section{RESULTS AND DISCUSSION}

All the classes of fatty acids in gariss prepared by starter cultures strains as well as the combination had variable trends during the study period.

\section{Short chains fatty acids (SCFA)}

The proportion of SCFA in gariss varied from 0.26 to $0.41 \%$ at $\mathrm{t}_{0}$ (milk) to $0.50-0.71 \%$ at $\mathrm{t}_{12 \mathrm{~h}}$ according to the type of starter (Table 1). However, there was some difference between the used starters. In gariss prepared by E. durans R03, E.faecium NWL, L. plantarum BJ6 and their combination, SFCA proportion significantly $(\mathrm{P} \leq 0.05)$ increased between $\mathrm{t}_{0}$ and the end of fermentation (Table 1). The same trend was found in the control during the same period of fermentation. This indicated that fermentation with or without using starter cultures increased SCFA during fermentation process, contrary to that was reported by Abdelrahman (2007) for which SCFA were lowered by fermentation of camel milk using different starter cultures. Konuspayeva et al. (2008) reported that camel milk has low content of short- chain fatty acids but the proportion reported was slightly higher $(1.16 \%)$.

\section{Medium chains fatty acids (MCFA)}

The proportion of MCFA in gariss varied from 14.99 to $15.36 \%$ at $\mathrm{t}_{0}$ (milk) to $14.59-15.96 \%$ at $\mathrm{t}_{12 \mathrm{~h}}$ according to the type of starter (Table 1). However, there was some 
Table 1: Effect of starter cultures and period of fermentation on gariss fatty acids chains

\begin{tabular}{|c|c|c|c|}
\hline Sample & SCFA & MCFA & LCFC \\
\hline \multicolumn{4}{|l|}{0 time } \\
\hline A & $(0.35)^{\mathrm{hijk}} \pm 0.05$ & $(15.36)^{\prime} \pm 0.07$ & $(84.29)^{m} \pm 2.50$ \\
\hline B & $(0.41)^{\mathrm{fgh}} \pm 0.07$ & $(14.99)^{\prime} \pm 0.10$ & $(84.60)^{i} \pm 2.63$ \\
\hline $\mathrm{C}$ & $(0.41)^{\mathrm{fgh}} \pm 0.07$ & $(14.99)^{\prime} \pm 0.10$ & $(84.60)^{i} \pm 2.36$ \\
\hline $\mathrm{D}$ & $(0.29)^{j \mathrm{kl}} \pm 0.05$ & $(15.11)^{\mathrm{k}} \pm 0.11$ & $(84.60)^{i} \pm 2.46$ \\
\hline$F$ & $(0.26)^{\mathrm{k}} \pm 0.05$ & $(15.13)^{k} \pm 0.40$ & $(84.61)^{\mathrm{h}} \pm 2.45$ \\
\hline \multicolumn{4}{|l|}{$3 \mathrm{~h}$} \\
\hline A & $(0.62)^{\mathrm{abc}} \pm 0.17$ & $(15.69)^{9} \pm 0.36$ & $(83.69)^{r} \pm 2.51$ \\
\hline B & $(0.39)^{g h_{i}} \pm 00$ & $(15.04)^{\prime} \pm 0.13$ & $(84.57)^{\mathrm{i}} \pm 2.63$ \\
\hline C & $(0.59)^{\mathrm{bcd}} \pm 0.05$ & $(16.43)^{\mathrm{b}} \pm 0.21$ & $(82.98)^{\vee} \pm 2.45$ \\
\hline D & $(0.47)^{\mathrm{efg}_{ \pm}} \pm 0.13$ & $(16.21)^{c} \pm 0.43$ & $(83.32)^{u} \pm 2.50$ \\
\hline$F$ & $(0.31)^{\mathrm{j} k \mathrm{k}} \pm 0.08$ & $(13.77)^{\circ} \pm 0.50$ & $(85.92)^{c} \pm 2.59$ \\
\hline \multicolumn{4}{|l|}{$6 \mathrm{~h}$} \\
\hline A & $(0.57)^{\mathrm{cd}} \pm 0.11$ & $(12.50)^{r} \pm 0.69$ & $(86.93)^{a} \pm 2.53$ \\
\hline B & $(0.68)^{\mathrm{ab}} \pm 0.11$ & $(13.12)^{P} \pm 0.75$ & $(86.2)^{b} \pm 2.14$ \\
\hline C & $(0.45)^{\mathrm{efg}} \pm 0.12$ & $(20.41)^{a} \pm 0.77$ & $(79.14)^{y} \pm 2.11$ \\
\hline D & $(0.25)^{\prime} \pm 0.06$ & $(16.47)^{\mathrm{b}} \pm 0.12$ & $(83.28)^{w} \pm 1.85$ \\
\hline $\mathrm{F}$ & $(0.28)^{\mathrm{k}} \pm 0.06$ & $(15.37)^{i} \pm 0.35$ & $(84.35)^{\prime} \pm 1.34$ \\
\hline \multicolumn{4}{|l|}{$9 \mathrm{~h}$} \\
\hline A & $(0.27)^{\mathrm{kl}} \pm 0.07$ & $(14.6)^{m} \pm 0.86$ & $(85.13)^{e} \pm 2.17$ \\
\hline B & $(0.38)^{g h i j} \pm 0.1$ & $(13.94)^{n} \pm 0.45$ & $(85.68)^{d} \pm 2.30$ \\
\hline C & $(0.33)^{\mathrm{gijk}} \pm 0.08$ & $(15.22)^{\prime} \pm 0.21$ & $(84.45)^{k} \pm 2.31$ \\
\hline D & $(0.54)^{\mathrm{cde}} \pm 0.13$ & $(15.89)^{\mathrm{e}} \pm 0.05$ & $(83.57)^{\mathrm{s}} \pm 2.38$ \\
\hline$F$ & $(0.53)^{\mathrm{cde}} \pm 0.09$ & $(15.77)^{\dagger} \pm 0.57$ & $(83.7)^{P} \pm 2.42$ \\
\hline \multicolumn{4}{|l|}{$12 \mathrm{~h}$} \\
\hline A & $(0.71)^{a} \pm 0.11$ & $(14.64)^{m} \pm 0.64$ & $(84.65)^{9} \pm 2.37$ \\
\hline B & $(0.52)^{\mathrm{de}} \pm 0.12$ & $(15.2)^{\mathrm{j}} \pm 0.38$ & $(84.28)^{n} \pm 2.37$ \\
\hline C & $(0.67)^{\mathrm{ab}} \pm 0.12$ & $(14.59)^{\mathrm{m}} \pm 0.17$ & $(84.74)^{\dagger} \pm 2.55$ \\
\hline D & $(0.50)^{\mathrm{def}} \pm 0.15$ & $(15.96)^{d} \pm 0.66$ & $(83.54)^{t} \pm 2.38$ \\
\hline $\mathrm{F}$ & $(0.62)^{\mathrm{abc}} \pm 0.14$ & $(15.6)^{\mathrm{h}} \pm 0.14$ & $(83.78)^{\circ} \pm 2.4$ \\
\hline
\end{tabular}

Values are means \pm (standard deviation) - Means not sharing a common superscript letter in a column are significantly different at. $P \geq 0.05$ as assessed by Duncan's multiple-range test. A: E. durans R03, B: E. faecium NWL, C: L. plantarum BJ6, D: Combination and F: The control

difference between the used starters. MCFA of gariss prepared by E. durans R03 and L. plantarum BJ6 decreased significantly $(\mathrm{P} \leq 0.05)$ between $\mathrm{t}_{0}$ and $\mathrm{t}_{12 \mathrm{~h}}$, while in gariss prepared by E.faecium $N W L$ and their combination it increased significantly $(\mathrm{P} \leq 0.05)$, similar trend being found in the control during the same period of fermentation (Table 1). Abdelrahman (2007) reported that starter cultures fermentation of camel milk increased MCFA from $12.79 \%$ for raw camel milk to $17.92,17.89,18.70$, 18.15 and $18.66 \%$ for camel milk fermented by Lactobacillus acidophilus, Lactobacillus bulgaricus, Lactococcus lactis, Streptococcus thermophilus and the Yoghurt culture (Lactobacillus bulgaricus: Streptococcus thermophilus), respectively.

\section{Long chains fatty acids (LCFA)}

For the LCFA the proportion in gariss varied from 84.29 to $84.61 \%$ at $\mathrm{t}_{0}$ (milk) to $83.54-84.74 \%$ at $\mathrm{t}_{12 \mathrm{~h}}$ according to the type of starter (Table 1). However, there was some difference between the used starters.
Table 2: Effect of starter cultures and period of fermentation on gariss fatty acids saturation status

\begin{tabular}{|c|c|c|c|c|}
\hline Sample & SFA & USFA & MUSFA & PUSFA \\
\hline \multicolumn{5}{|l|}{0 time } \\
\hline A & $(66.57)^{g} \pm 2.02$ & $(33.43)^{ \pm} \pm 2.10$ & $(29.43)^{\mathrm{ij}} \pm 3.05$ & $(4.0)^{g h i} \pm 00$ \\
\hline B & $(61.25)^{r} \pm 2.17$ & $(38.75)^{c} \pm 2.55$ & $(32.38)^{c} \pm 000$ & $(6.37)^{\dagger} \pm 1.50$ \\
\hline C & $(61.25)^{r} \pm 2.17$ & $(38.75)^{c} \pm 2.55$ & $(32.38)^{c} \pm 000$ & $(6.37)^{\ddagger} \pm 1.74$ \\
\hline D & $(63.77)^{\prime} \pm 2.60$ & $(36.23)^{\ddagger} \pm 2.12$ & $(32.48)^{c} \pm 1.15$ & $(3.75)^{\mathrm{hi}} \pm 2.50$ \\
\hline$F$ & $(64.24)^{k} \pm 2.79$ & $(35.76)^{g} \pm 1.85$ & $(31.63)^{\mathrm{de}} \pm 2.14$ & $4 \quad(4.13)^{g h_{i}} \pm 00$ \\
\hline \multicolumn{5}{|l|}{$3 \mathrm{~h}$} \\
\hline A & $(62.25)^{P} \pm 2.17$ & $(37.75)^{d} \pm 2.03$ & $(33.71)^{\mathrm{b}} \pm 3.40$ & $(4.04)^{g h_{i}} \pm 1.04$ \\
\hline B & $(68.22)^{c} \pm 2.54$ & $(31.78)^{\prime} \pm 1.99$ & $(28.31)^{\mathrm{kl}} \pm 1.60$ & $(3.47)^{i} \pm 1 . / 47$ \\
\hline C & $(67.24)^{\mathrm{e}} \pm 2.57$ & $(32.76)^{\mathrm{k}} \pm 2.01$ & $(28.9)^{j \mathrm{k}} \pm 3.80$ & $(3.86)^{g h i} \pm 0.86$ \\
\hline $\mathrm{D}$ & $(72.15)^{b} \pm 2.25$ & $(27.85)^{\mathrm{m}} \pm 2.03$ & $(25.06)^{\mathrm{m}} \pm 4.00$ & $(2.79)^{\mathrm{i}} \pm 1.79$ \\
\hline$F$ & $(67.97)^{d} \pm 2.74$ & $(32.03)^{\prime} \pm 2.05$ & $(21.97)^{\mathrm{n}} \pm 4.60$ & $(10.06)^{c} \pm 1.06$ \\
\hline \multicolumn{5}{|l|}{$6 \mathrm{~h}$} \\
\hline A & $(52.71)^{\mathrm{u}} \pm 2.21$ & $(47.29)^{\mathrm{a}} \pm 2.09$ & $(28.07)^{\prime} \pm 1.00$ & $(19.22)^{a} \pm 1.22$ \\
\hline B & $(55.67)^{t} \pm 2.76$ & $(44.33)^{\mathrm{b}} \pm 2.18$ & $(29.15)^{j} \pm 5.00$ & $(15.18)^{b} \pm 2.36$ \\
\hline C & $(85.65)^{a} \pm 3.65$ & $(14.35)^{n} \pm 2.23$ & $(12.69)^{\circ} \pm 3.60$ & $(1.66)^{k} \pm 0.66$ \\
\hline D & $(66.99)^{\dagger} \pm 2.89$ & $(33.01)^{j \mathrm{k}} \pm 2.22$ & $(28.9)^{j \mathrm{k}} \pm 3.20$ & $(4.11)^{g h i} \pm 1.11$ \\
\hline $\mathrm{F}$ & $(64.93)^{i} \pm 2.03$ & $(35.07)^{\mathrm{h}} \pm 2.28$ & $(30.7)^{\mathrm{fg}} \pm 2.20$ & $(4.37)^{g h} \pm 2.37$ \\
\hline \multicolumn{5}{|l|}{$9 \mathrm{~h}$} \\
\hline A & $(64.86)^{i} \pm 2.15$ & $(35.14)^{\mathrm{h}} \pm 1.90$ & $(31.27)^{\mathrm{ef}} \pm 3.18$ & $(3.87)^{g h i} \pm 1.87$ \\
\hline B & $(61.09)^{\mathrm{s}} \pm 1.80$ & $(38.91)^{c} \pm 1.79$ & $(34.45)^{a} \pm 1.24$ & $(4.46)^{g} \pm 0.92$ \\
\hline C & $(63.17)^{n} \pm 2.11$ & $(36.83)^{\mathrm{e}} \pm 1.92$ & $(33.21)^{\mathrm{b}} \pm 2.30$ & $(3.62)^{i} \pm 1.24$ \\
\hline D & $(66.04)^{\mathrm{h}} \pm 2.51$ & $(33.96)^{i} \pm 2.41$ & $(29.91)^{\mathrm{hi}} \pm 2.28$ & $(4.05)^{g h} \pm 1.05$ \\
\hline$F$ & $(65.20)^{i} \pm 1.56$ & $(34.80)^{\mathrm{h}} \pm 2.08$ & $(31.23)^{\mathrm{ef}} \pm 1.27$ & $(3.57)^{i} \pm 1.57$ \\
\hline \multicolumn{5}{|l|}{$12 \mathrm{~h}$} \\
\hline A & $(62.51)^{\circ} \pm 2.75$ & $(37.49)^{d} \pm 2.26$ & $(29.50)^{\mathrm{i}} \pm 2.40$ & $(7.99)^{d} \pm 0.99$ \\
\hline B & $(63.53)^{m} \pm 2.25$ & $(36.47)^{\mathrm{ef}} \pm 3.04$ & $(30.71)^{\mathrm{fg}} \pm 1.71$ & $(5.76)^{f} \pm 0.76$ \\
\hline C & $(61.10)^{s} \pm 2.74$ & $(38.90)^{c} \pm 2.46$ & $(31.91)^{\mathrm{cd}} \pm 2.91$ & $(6.99)^{\mathrm{e}} \pm 0.99$ \\
\hline D & $(66.13)^{\mathrm{h}} \pm 2.21$ & $(33.87)^{i} \pm 2.14$ & $(30.21)^{\mathrm{gh}} \pm 1.25$ & $(3.66)^{i} \pm 0.66$ \\
\hline$F$ & $(64.94)^{i} \pm 2.76$ & $(35.06)^{\mathrm{h}} \pm 2.23$ & $(32.33)^{c} \pm 2.33$ & $(2.73)^{i} \pm 0.73$ \\
\hline
\end{tabular}

Values are means \pm (standard deviation) - Means not sharing a common superscript letter in a column are significantly different at $P \geq 0.05$ as assessed by Duncan's multiple-range test. A: E.durans R03, B: E. faecium NWL, C: L. plantarum BJ6, D: Combination and F: The control

LCFA of gariss prepared by E. durans R03 and L. plantarum BJ6 significantly $(\mathrm{P} \leq 0.05)$ increased between $\mathrm{t}_{0}$ and $\mathrm{t}_{12 \mathrm{~h}}$ (Table 1), while LCFA in gariss prepared by E. faecium $N W L$ and their combination it decreased significantly $(\mathrm{P} \leq 0.05)$ during the fermentation process, the same trend being found in the control. Abdelrahman (2007) reported that starter cultures fermentation of camel milk increased LCFA from $78.54 \%$ for raw camel milk to 92.11, 91.61, $91.35,91.83$ and $91.14 \%$ for camel milk fermented by Lb. acidophilus, Lb. bulgaricus, L. lactis, S. thermophilus and the Yoghurt culture (Lb. bulgaricus: S. thermophilus), respectively.

\section{Saturated fatty acids (SFA)}

For SFA, the proportion is passing from 61.25to 66.57\% at $\mathrm{t}_{0}$ (milk) to $61.10-66.13 \%$ at $\mathrm{t}_{12 \mathrm{~h}}$ according to the type of starter (Table 2). However, there was some difference between the used starters.

SFA of gariss prepared by E. durans R03 and L. plantarum BJ6 significantly $(P \leq 0.05)$ decreased between $t_{0}$ and $t_{12 h}$ 


\begin{tabular}{|c|c|c|c|}
\hline Sample & Omega3 & Omega6 & US/SFA \\
\hline \multicolumn{4}{|l|}{0 time } \\
\hline A & $(0.56)^{i} \pm 00$ & $(3.05)^{\mathrm{ab}} \pm 0.05$ & $(0.50)^{\mathrm{hij}} \pm 00$ \\
\hline B & $(0.56)^{i} \pm 00$ & $(2.77)^{\mathrm{abc}} \pm 00$ & $(0.63)^{\mathrm{cd}} \pm 0.13$ \\
\hline C & $(0.56)^{i} \pm 00$ & $(2.77)^{\mathrm{abc}} \pm 00$ & $(0.63)^{\mathrm{cd}} \pm 0.13$ \\
\hline $\mathrm{D}$ & $(0.45)^{n} \pm 0.12$ & $(2.9)^{\mathrm{abc}} \pm 0.13$ & $(0.57)^{\text {defg }} \pm 0.07$ \\
\hline $\mathrm{F}$ & $(0.87)^{\mathrm{b}} \pm 00$ & $(2.85)^{\mathrm{abc}} \pm 0.12$ & $(0.56)^{\mathrm{efgh}^{\prime}} \pm 000$ \\
\hline \multicolumn{4}{|l|}{$3 \mathrm{~h}$} \\
\hline A & $(0.87)^{\mathrm{b}} \pm 00$ & $(2.74)^{\mathrm{abc}} \pm 0.13$ & $(0.60)^{\text {cde }} \pm 000$ \\
\hline B & $(0.53)^{\mathrm{j}} \pm 0.03$ & $(2.91)^{\mathrm{abc}} \pm 0.90$ & $(0.47)^{\mathrm{i}} \pm 0.13$ \\
\hline C & $(0.31)^{t} \pm 0.23$ & $(2.23)^{\mathrm{cd}} \pm 0.46$ & $(0.49)^{\mathrm{ij}} \pm 0.14$ \\
\hline D & $(0.46)^{m} \pm 0.12$ & $(1.97)^{d} \pm 0.12$ & $(0.39)^{k} \pm 0.13$ \\
\hline $\mathrm{F}$ & $(0.37)^{\mathrm{s}} \pm 0.19$ & $(2.41)^{\mathrm{bcd}} \pm 0.12$ & $(0.47)^{\dagger} \pm 0.13$ \\
\hline \multicolumn{4}{|l|}{$6 \mathrm{~h}$} \\
\hline$A$ & $(0.40)^{\mathrm{P}} \pm 0.16$ & $(2.48)^{\mathrm{abcd}} \pm 0.13$ & $(0.90)^{a} \pm 000$ \\
\hline B & $(0.27)^{\mathrm{u}} \pm 0.12$ & $(2.56)^{\mathrm{abcd}} \pm 00$ & $(0.80)^{\mathrm{b}} \pm 000$ \\
\hline C & $(0.05)^{\mathrm{w}} \pm 00$ & $(1.29)^{\mathrm{e}} \pm 1.20$ & $(0.17)^{\prime} \pm 0.05$ \\
\hline D & $(0.65)^{e} \pm 0.12$ & $(3.08)^{\mathrm{ab}} \pm 1.1$ & $(0.49)^{\mathrm{ij}} \pm 0.12$ \\
\hline $\mathrm{F}$ & $(0.99)^{\mathrm{a}} \pm 0.12$ & $(2.98)^{\mathrm{ab}} \pm 0.12$ & $(0.54)^{\text {efghi }} \pm 0.12$ \\
\hline \multicolumn{4}{|l|}{$9 \mathrm{~h}$} \\
\hline A & $(0.64)^{\dagger} \pm 0.08$ & $(2.96)^{\mathrm{ab}} \pm 0.13$ & $(0.54)^{\text {efghi }} \pm 0.13$ \\
\hline B & $(0.50)^{k} \pm 0.06$ & $(2.83)^{\mathrm{abc}} \pm 0.83$ & $(0.64)^{c} \pm 000$ \\
\hline C & $(0.59)^{g} \pm 0.13$ & $(2.95)^{\mathrm{ab}} \pm 0.13$ & $(0.58)^{\text {cdef }} \pm 000$ \\
\hline D & $(0.74)^{d} \pm 0.12$ & $(3.14)^{a} \pm 0.14$ & $(0.51)^{g h i j} \pm 0.12$ \\
\hline$F$ & $(0.58)^{n} \pm 0.16$ & $(3.02)^{\mathrm{ab}} \pm 0.12$ & $(0.53)^{\mathrm{fghij}} \pm 0.13$ \\
\hline \multicolumn{4}{|l|}{$12 \mathrm{~h}$} \\
\hline A & $(0.76)^{c} \pm 0.16$ & $(2.93)^{\mathrm{ab}} \pm 0.13$ & $(0.60)^{\mathrm{cde}} \pm 00$ \\
\hline B & $(0.41)^{\circ} \pm 0.15$ & $(2.95)^{\mathrm{ab}} \pm 0.12$ & $(0.57)^{\text {defg }} \pm 0.14$ \\
\hline C & $(0.49)^{\prime} \pm 0.12$ & $(2.80)^{\mathrm{abc}} \pm 0.80$ & $(0.64)^{c} \pm 0.14$ \\
\hline D & $(0.38)^{r} \pm 0.17$ & $(3.10)^{\mathrm{ab}} \pm 1.10$ & $(0.51)^{g h i j} \pm 0.11$ \\
\hline $\mathrm{F}$ & $(0.45)^{n} \pm 0.16$ & $(2.98)^{\mathrm{ab}} \pm 0.14$ & $(0.54)^{\text {efgh }} \pm 0.12$ \\
\hline
\end{tabular}

Values are means \pm (standard deviation) - Means not sharing a common superscript letter in a column are significantly different at $P \geq 0.05$ as assessed by Duncan's Multiple-Range Test. A: E.durans R03, B=E. faecium NWL, C: L. plantarum BJ6, D: Combination and F: The control

(Table 1), while in gariss prepared by E.faecium NWL and their combination significantly $(\mathrm{P} \leq 0.05)$ increased during the same sequence, similar trend being found in the control during the same period of fermentation. For Abdelrahman (2007) starter cultures for fermentation of camel milk increased SFA from $40.80 \%$ for raw camel milk to 73.92 , 73.31, 74.90, 74.4 and 74.16\% for camel milk fermented by Lactobacillus acidophilus, Lactobacillus bulgaricus, Lactococcus lactis, Streptococcus thermophilus and the Yoghurt culture (Lactobacillus bulgaricus: Streptococcus thermophilus), respectively.

\section{Unsaturated fatty acids (USFA)}

The proportion of USFA is passing from 61.25to $66.57 \%$ at $\mathrm{t}_{0}$ (milk) to $61.10-66.13 \%$ at $\mathrm{t}_{12 \mathrm{~h}}$ according to the type of starter (Table 2). However, there was some difference between the used starters.

USFA of gariss prepared by E. durans R03 significantly $(\mathrm{P} \leq 0.05)$ increased between zero time and the end of fermentation period; while the USFA of gariss prepared by E. faecium NWL and their combination significantly $(\mathrm{P} \leq 0.05)$ decreased(Table 1$)$, the same trend being found in the control during the same period of fermentation. Gariss prepared by L. plantarum BJ6 single culture was not affected by the period of fermentation process. Abdelrahman (2007) reported that the fermentation of camel milk decreased USFA from $38.74 \%$ for raw camel milk to 36.27, 36.69, 35.49, 35.92 and 35.85\% for camel milk fermented by $L b$. acidophilus, $L b$. bulgaricus, L. lactis, S. thermophilus and the Yoghurt culture (Lb. bulgaricus: S. thermophilus), respectively.

\section{Mono-unsaturated fatty acids (MUSFA)}

The proportion of MUSFA varied from 61.25to 66.57\% at $\mathrm{t}_{0}$ (milk) to $61.10-66.13 \%$ at $\mathrm{t}_{12 \mathrm{~h}}$ according to the type of starter (Table 2). However, there was some difference between the used starters.

The proportion of MUSFA of gariss prepared by E. durans $\mathrm{R} 03$ and L. plantarum BJ6 were not changing between $\mathrm{t}_{0}$ and $\mathrm{t}_{12 \mathrm{~h}}$, while in gariss prepared by E.faecium NWL and their combination it decreased significantly $(\mathrm{P} \leq 0.05)$ at the same time (Table 1). The MUSFA of the control significantly $(\mathrm{P} \leq 0.05)$ increased during the same period of fermentation. From his part, Abdelrahman (2007) reported that starter cultures fermentation of camel milk lowered MUSFA from $34.18 \%$ for raw camel milk to $30.97,31.2,30.30,30.37$ and $30.72 \%$ for camel milk fermented by $L b$. acidophilus, Lb. bulgaricus, L. lactis, S. thermophilus and the Yoghurt culture (Lb. bulgaricus: S. thermophilus), respectively.

\section{Poly unsaturated fatty acids (PUSFA)}

The quantity in proportion of PUSFA is passing from 61.25 to $66.57 \%$ at $\mathrm{t}_{0}$ (milk) to $61.10-66.13 \%$ at $\mathrm{t}_{12 \mathrm{~h}}$ according to the type of starter (Table 2). However, there was some difference between the used starters.

PUSFA of gariss prepared by E. durans R03 and L. plantarum BJ6 significantly $(\mathrm{P} \leq 0.05)$ increased between $\mathrm{t} 0$ and $\mathrm{t}_{12 \mathrm{~h}}$ while PUSFA in gariss prepared by E.faecium NWL significantly $(\mathrm{P} \leq 0.05)$ decreased, the same trend being found in the control (Table 1). The proportion of MUSFA of gariss prepared by the combination was not changing during all fermentation process. This result is reverse to that reported by Abdelrahman (2007) who reported that starter cultures fermentation of camel milk increased PUSFA from $4.56 \%$ for raw camel milk to 5.30, 5.49, 5.19, 5.55 and $5.13 \%$ for camel milk fermented by Lb. acidophilus, Lb. bulgaricus, L. lactis, S. thermophilus and the Yoghurt culture (Lb. bulgaricus: S. thermophilus), respectively.

\section{$\mathrm{Omega}_{3}$ and omega ${ }_{6}$ fatty acids}

The $\omega_{3}$ and $\omega_{6}$ fatty acids are in low proportion in milk and gariss. The range was $0.45-0.87$ and $0.38-0.76 \%$ at $\mathrm{t}_{0}$ and $\mathrm{t}_{12 \mathrm{~h}}$ 
respectively for $\omega_{3}$, and $2.77-3.05$ and $2.8-3.1 \%$ for $\omega_{6}$ in the same time (Table 2).

The $\omega_{3}$ and $\omega_{6}$ fatty acids of gariss had opposite behavior during fermentation process (Table 3 ). While $\omega_{3}$ in gariss prepared by E. durans R03 significantly $(\mathrm{P} \leq 0.05)$ increased, $\omega_{6}$ decreased. Elsewhere, in gariss prepared by E.faecium NWL, L. plantarum BJ6 as well as their combination, $\omega_{3}$ lowered significantly $(\mathrm{P} \leq 0.05)$ between $\mathrm{t}_{0}$ and $\mathrm{t}_{12 \mathrm{~h}}$ while it increased for $\omega 6$. No $\omega_{3}$ or $\omega_{6}$ fatty acids were found or determined in raw and fermented camel milk (Abdelrahman, 2007; Konuspayeva et al., 2008; Faye et al., 2008).

\section{Unsaturated fatty acids to saturated fatty acids ratio USFA/SFA}

The ratios of USFA/SFA of gariss prepared by E. durans R03 significantly $(\mathrm{P} \leq 0.05)$ increased between $\mathrm{t}_{0}$ and $\mathrm{t}_{12 \mathrm{~h}}$, while that of gariss prepared by E.faecium NWL, L. plantarum BJ6 as well as their combination were not significantly $(\mathrm{P} \leq 0.05)$ affected, similar trend being found in the control. At reverse, Abdelrahman (2007) reported that the starter cultures fermentation of raw camel milk lowered ratio of unsaturated to saturated fatty acids from 0.95 for raw camel milk to $0.49,0.50,0.47,0.48$ and 0.48 for camel milk fermented by $L b$. acidophilus, $L b$. bulgaricus, $L$. lactis, S. thermophilus and the Yoghurt culture (Lb. bulgaricus: S. thermophilus), respectively. Finally, it appears that fermentation process with E. durans R03 increases, SCFA, LCFA, SFA,USFA, MUSFA, PUSFA, Omega3 and the ratio of US/SFA and decreases, MCFA, Omega6 in camel milk, while with E. faecium increases SCFA,SFA, MUSFA, PUSFA, Omega 3 and the ratio of US/SFA and decreases MCFA, LCFA, USFA, Omega6 in camel milk, and that with L. plantarum BJ6 increases SCFA, LCFA, USFA, PUSFA, Omega 6 and the ratio of US/SFA and decreases MCFA, SFA, MUSFA, Omega3 in camel milk, the combination of those strains increases SCFA, MCFA, SFA, Omega6, and decreases, LCFA, USFA, MUSFA, PUSFA Omega3 and the ratio of US/SFA in camel milk. The spontaneous fermentation (the control) increases SCFA, MCFA, SFA, MUSFA, Omega6 and decreases LCFA, USFA, PUSFA, Omega3 and the ratio of US/SFA in camel milk. The different trends on the effect of the different strains used as starter for the fermentation of camel milk.

Guler and Gursoy-Balci (2011) reported that the type of cultures storage periods had no effect on long-chain free fatty acids in yogurts from goat milk. During the storage, short-chain free fatty acids were different according to culture type used and increased during storage, while the levels of medium-chain free fatty acids, except for decanoic acid, were unchanged and the amount of long-chain free fatty acids decreased during storage.
As far as we know, our paper is the first attempt to use E.faecium, E.durans and L. plantarum as starter culture to produce fermented camel milk (gariss) in the laboratory conditions. LAB distribution showed a high diversity of species that are dominant and was frequently described in various dairy products. In fermented camel milk from Kazakhstan called Shubat different microorganisms were identified as Enterococcus durans; Enterococcus faecalis; Enterococcus faecium and others (Akhmetsadykova et al., 2014). By using well identified starter cultures of LAB strains associated with gariss preparation and by controlling the conditions of product preparation, a wholes me product of consistent quality will be desired for the consumers of the urban areas. That will lead to the commercialization of gariss product where fresh milk is procured by nomads in the remote areas. Consequently, it could be one of the most income generating activities that can give great push to those people of the remote areas.

\section{CONCLUSION}

The fatty acids classes of fermented camel milk have various trends affected by starter cultures fermentation. The uses of some species such as E. duransR03, E.faecium NWL and L. plantarum BJ6 in production of laboratory scale fermented camel milk gariss, suggests their possible use as starter culture in the manufacture of commercially gariss products. However, more studies are needed to complete the isolation and characterization of new LAB strains that could be present in camel milk produced in Sudan and to compare the results with reports from other countries and regions. Also, the organoleptic analysis of the gariss produced under the above mentioned conditions are also recommended for further studies.

\section{Authors' contributions}

This work was carried out in collaboration between all authors. Ahmed designed the study and wrote the protocol, Faye interpreted the data. Mohemed and Yousif supervised the field study, gathered the initial data and performed preliminary data analysis. Also Ahmed and Faye managed the literature searches and produced the initial draft. Loiseau managed the Laboratory work for Ahmed during his stay in France. All authors read and approved the final manuscript.

\section{REFERENCES}

Abdel Rahman, I. E., H. A. Dirar and M. A. Osman. 2009. Microbiological and chemical changes and sensory evaluation of camel milk fermented by selected bacterial starter cultures. Afr. J. Food Sci. 3: 398-405.

Abdelgadir, W. S., T. K. Ahmed and H. A. Dirar. 1998. The traditional fermented milk products of the Sudan. Int. J. Food Microbiol. 44: 1-13. 
Abdelrahman, I. E. 2007. Biochemical Changes in Camel Milk Fermented by Bacterial starter Culture, Ph.D. Thesis, Faculty of Agriculture, University of Khartoum, Khartoum North, Shambat, Sudan.

Abeiderrahmane, N. 2005. Modern dairy products from traditional camel herding, an experience in Mauritania. In: Faye, B. and P. Esenov, (Eds.), Desertification Combat and Food Safety: The Added Value of Camel Producers. NATO Science Series, IOS Press, Amsterdam, the Netherlands, Pp. 152-157.

Akhmetsadykova, S., A. Baubekova, G. Konuspayeva, N. Akhmetsadykov and G. Loiseau. 2014. Microflora identification of fresh and fermented camel milk from Kazakhstan. Emirates J. Food Agric. 26(4): 327-332.

Dirar, H. A. 1993. The Indigenous Fermented Foods of the Sudan. A Study in Africa Food and Nutrition, CAB International, England.

Faye, B. and G. Konuspayeva. 2012. The sustainability challenge of the dairy sector - The growing importance of the non-cattle milk production worldwide. Int. Dairy J. 24: 50-56.

Faye, B., G. Konuspayeva, M. Narmuratova and G. Loiseau. 2008. Comparative fatty acid gross composition of milk in Bactrian camel, and dromedary. J. Camelid Sci. 1: 48-53.

Guler, Z. and A. C. Gursoy-Balci. 2011. Evaluation of volatile compounds and free fatty acids in set types yogurts made of ewes', goats' milk and their mixture using two different commercial starter cultures during refrigerated storage. Food Chem. 127: 1065-1071.

Hassan, R. A., I. E. M. Elzubier and S. A. Babiker. 2008. Chemical and microbial measurements of fermented camel milk (Gariss) from transhumance and Nomadic herds in Sudan. Aust. J. Basic Appl. Sci. 2(4): 800-804.
Konuspayeva, G., E. Lemarie, B. Faye, G. Loiseau and D. Montet. 2008. Fatty acid and cholesterol composition of camel's (Camelus bactrianus, Camelus dromedarius and hybrids) milk in Kazakhstan. Dairy Sci. Technol. 88: 327-340.

Konuspayeva, G. and B. Faye. 2011. Identity, therapeutic virtues and health claims: the fermented products in Central Asia. In: OCHA exercise books. Coll, Vol. 15. Milk culture of the world, Paris, 5-6 Mai, 2010; Pp. 135-145.

Lore, T. A., S. K. Mbugua and J. Wangoh. 2005. Enumeration and identification of microflora in Suusac, a Kenyan traditional fermented camel milk product. Lebensm. Wiss. U. Technol. 38: 125-130.

Nagy, P., S. Thomas, O. Marko and J. Juhasz. 2013. Milk production, raw milk quality and fertility of dromedary camels (Camelus dromedarius) under intensive management. Acta Vet. Hung. 61: 71-84. http://dx.doi.org/10.1556/AVet.2012.051.

Sabia, C., G. Manicarda, P. Messai, S. De Niederhansern and M. Bondi. 2002. Enterocin $416 \mathrm{~K} 1$, an antilisterial bacteriocin produced by Enterococcus casseliflavus IM 416 K1 isolated from Italian sausages. Int. J. Food Microbiol. 75: 163-170.

Seifu, E., A. Abraham, M. Y. Kurtu and Z. Yilma. 2012. Isolation and characterization of lactic acid bacteria from Ititu: Ethiopian traditional fermented camel milk. J. Camelid Sci. 5: 82-98. Available from: http://www.isocard.org. [Last Assessed on 14/02/16].

Suleiman, A. E., R. Osawa and R. Tsenkova. 2007. Isolation and identification of Lactobacilli from Gariss, a Sudanese fermented camel milk product. Res. J. Microbiol. 2(2): 125-132.

Yagil, R. 1982. Camels and Camel Milk. FAO Animal Production and Health Paper, Rome, Italy. Available from: http://www.fao.org. [Last Assessed on 14/02/16] 